\title{
Early nasal continuous positive airway pressure in preterm neonates with Respiratory Distress Syndrome.
}

1. MBBS, DCH, FCPS (Pediatrics), FCPS (Neonatology)

Assistant Professor Neonatology Children Hospital and Institute of Child Health, Multan.

2. MBBS, FCPS (Pediatrics) Assistant Professor

Bakhtawar Ameen Medical \& Dental College Multan.

3. MBBS, MCPS (Pediatrics)

Admin Registrar Neonatology Children Hospital and Institute of Child Health, Multan

4. MBBS, FCPS (Pediatrics), FCPS (Neonatology)

Senior Registrar Neonatology Children Hospital and Institute of Child Health, Multan

5. MBBS, FCPS (Pediatrics)

Professor of Emiratus

Children Hospital and Institute of Child Health, Multan.

\section{Correspondence Address:}

Dr. Abdur Rehman

Assistant Professor of Neonatology Al-Rahim colony prince Hotel Street Nishtar road near Nishtar flyover Multan.

dr.armalik@outlook.com

Article received on:

20/07/2020

Accepted for publication:

$02 / 11 / 2020$

\section{INTRODUCTION}

Neonatal respiratory distress syndrome (RDS) is known to be a developmental disorder and more commonly noted among preterm infants. ${ }^{1}$ Structural immaturity related to lungs along with deficit and dysfunction of the surfactant are some of the major issues linked to progression of newborns to RDS. Recent decades have seen lots of advancement in the preventive as well as management strategies of RDS among neonates but still it is considered a significant cause of morbidity and mortality among neonates. ${ }^{2}$

World Health Organization (WHO) calculated that more than 1.1 million preterm babies die annually. In the developing countries, around $12 \%$ of the newborns are premature while Pakistan is among the top 10 countries where high incidence of premature births is noted. ${ }^{3}$ In Pakistan, 15.8 per 100 births are calculated to be preterm newborns annually. ${ }^{3}$ Bhutta ZA and Yusuf $\mathrm{K}$ from Karachi reported prevalence of RDS as $12.8 \%$ among low birth-weight babies. In these, mortality was noted to be $39 \%$ while highest rates of mortality were noted among those who had birth-weight $<$ $1000 \mathrm{~g} .{ }^{4}$ Khan MR et al also noted prevalence of RDS to be $35.5 \%$ among preterm newborns while mortality among these neonates were noted to be $14 \% .^{5}$

"Intermittent positive pressure ventilation" (IPPV) along with surfactant has long been considered to be standard form of treatment for RDS. ${ }^{6}$ Gregory GA et al in 1971 proposed continuous 
positive airway pressure (CPAP) as another way of improving oxygenation among infants having idiopathic RDS. ${ }^{7}$ IPPV is an invasive method and contributes to airway and lung injury including the development of chronic lung disease. ${ }^{8}$

"Nasal Continuous Positive Airway Pressure (nCPAP)" has come out as the primary ventilatory support among neonates with RDS in the last couple of decades. CPAP has enabled us to adopt a less invasive CPAP for early treatment of RDS among newborns with an objective to intervene and facilitate avoidance of intubation and reducing mucociliary flow as well as risk of mucosal injury. CPAP has been noted to result in recruitment of alveoli, inflating collapsed alveoli and reducing inspiratory shunt. CPAP also raises mean airway pressure and enhances ventilation perfusion mismatch. CPAP has also been noted to conserve surfactant at alveolar surface.9,10

Not many local studies exist elaborating role of CPAP among preterm neonates with RDS. Utilizing nCPAP in a developing country like Pakistan is not without challenges. Lack of resources like inappropriate nurses to patient's ratio, deficiency of monitoring equipment, and cost related issues. Determining the efficacy of the utilization of nCPAP in developing countries like Pakistan will further guide authorities about scope and benefits of early CPAP. This study was aimed to assess the effectiveness of early nasal CPAP in preterm neonates with RDS.

\section{MATERIAL \& METHODS}

This study was conducted at "Department of Neonatology, Children's Hospital and Institute of Child Health, Multan", Pakistan, from September 2018 to June 2020.

Approval from "Institutional Ethical Committee" was sought for this study.

Sample size of 172 was calculated according to the formula: $n=z^{2}{ }^{*}$ * $(1-p) / e^{2}$

Where: $z=1.96$ for a confidence level (a) of 95\%, $\mathrm{p}=$ proportion $(12.8 \%)^{4}$, e = margin of error as $5 \%$.
A total of 172 neonates admitted to neonatal intensive care unit (NICU), having RDS with gestational age as 28 to 34 weeks were enrolled during the study period employing nonprobability consecutive sampling technique. RDS was defined as tachypnea (respiratory rate $>60 /$ minute), increased work of breathing (grunting, cyanosis, recessions) and having x-ray findings consistent with respiratory distress syndrome (RDS). Neonates having birth asphyxia, meconium aspiration syndrome, severe cardiac instability, congenital abnormalities, neuromuscular diseases, persistent prolonged apneas and worsening respiratory type 2 failure were note enrolled.

All study participants were administered early nasal CPAP (within 6 hours of onset of RDS). All babies with RDS were evaluated using SilvermanAnderson (SA) score, blood gas analysis and pulse oximetry. Babies with SA score of $>4$ or requiring $\mathrm{FiO}_{2}>30 \%$ to maintain $\mathrm{PaO}_{2} 60$ $90 \mathrm{~mm} \mathrm{Hg}$ were treated with early nCPAP and effectiveness was judged using SA scoring and blood gas analysis. If symptoms progress and $\mathrm{FiO}_{2}$ requirement is $>0.6$ to maintain $\mathrm{SpO}_{2} 90$ $-95 \%$, babies were ventilated. nCPAP was termed successful if saturation was $90-95 \% ; \mathrm{PaO}_{2}$ of 60 $90 \mathrm{~mm} \mathrm{Hg}, \mathrm{PaCO}_{2}$ of 35 to $45 \mathrm{~mm} \mathrm{Hg}$ and $\mathrm{pH}$ of 7.3 to 7.4 with $\mathrm{FiO}_{2}<0.6$, and if baby had no respiratory distress. nCPAP was termed as failure if $\mathrm{PaO}_{2}<50 \mathrm{~mm} \mathrm{Hg}$ or $\mathrm{PCO}_{2}>60 \mathrm{~mm} \mathrm{Hg}$ with $\mathrm{FiO}_{2}>0.6$, and SA score $>6$, along with recurrent apnea.

SPSS version 26.0 was used for data analysis. Qualitative variables were represented as frequencies as well as percentages while quantitative variables were shown as mean and standard deviation. Chi square test and student t-test were used to compare qualitative and quantitative variables respectively considering $P$ value $<0.05$ as significant.

\section{RESULTS}

Out of a total of 172 neonates, most, 91 (52.9\%) were mal nourished, 89 (51.7\%) had gestational age between 31 to 32 weeks and 97 (56.4\%) with birth-weight between 1000 to 1500 grams. 
Majority of the neonates, 97 (56.4\%) were found to have radiological grading of RDS as moderate. Characteristics of preterm neonates as distribution of gender, gestational age, birth weight, radiological grading of RDS and mean arterial blood gas parameters at the time of admission are given in Table-I. Mean age at the time of initiation of treatment was noted to be $4.68+2.14$ hours with range 1 to 6 hours.

\begin{tabular}{|c|c|c|}
\hline \multicolumn{2}{|c|}{ Study Variables } & Number (\%) \\
\hline \multirow{2}{*}{ Gender } & Male & 91 (52.9\%) \\
\hline & Female & $81(47.1 \%)$ \\
\hline \multirow{3}{*}{$\begin{array}{l}\text { Gestational } \\
\text { Age (weeks) }\end{array}$} & $28-30$ & $48(27.9 \%)$ \\
\hline & $31-32$ & $89(51.7 \%)$ \\
\hline & 33-34 & $35(20.3 \%)$ \\
\hline \multirow{3}{*}{$\begin{array}{l}\text { Birth Weight } \\
\text { (g) }\end{array}$} & $<999$ & $24(13.9 \%)$ \\
\hline & $1000-1500$ & $97(56.4 \%)$ \\
\hline & $1501-2000$ & $51(29.7 \%)$ \\
\hline \multirow{3}{*}{$\begin{array}{l}\text { Radiological } \\
\text { Grading of } \\
\text { RDS }\end{array}$} & Mid & $27(15.7 \%)$ \\
\hline & Moderate & 97 (56.4\%) \\
\hline & Severe & $48(27.9 \%)$ \\
\hline \multirow{4}{*}{$\begin{array}{l}\text { Arterial } \\
\text { Blood Gas } \\
\text { Parameters }\end{array}$} & $\mathrm{pH}($ Mean + SD) & $7.311+0.859$ \\
\hline & $\mathrm{PaO}_{2}($ Mean + SD & $56.75+10.85$ \\
\hline & $\mathrm{PCO}_{2}($ Mean $+\mathrm{SD})$ & $39.48+11.52$ \\
\hline & $\mathrm{HCO}_{3}($ Mean+SD) & $18.483+0.95$ \\
\hline
\end{tabular}

Outcome of nCPAP in the present study as successful was observed in 143 (83.1\%) neonates. Figure-1 depicts the outcome in terms of successful or unsuccessful outcome among study participants.

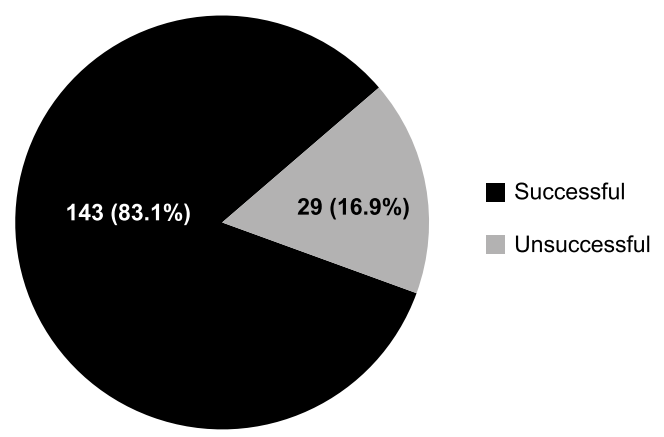

Figure-1. Outcome of early nCPAP in preterm neonates with RDS in the present study $(n=172)$

Table-Il shows distribution of nCPAP outcome with respect to study variables among study participants. There was no statistical difference in terms of nCPAP outcome among study participants with respect to gender $(p=0.4990)$. Gestational age, birth weight and severity of radiological grading of RDS were significantly associated with outcome of nCPAP ( $p<0.00001)$. Arterial blood gas parameters as $\mathrm{PaO}_{2}, \mathrm{PCO}_{2}$ and $\mathrm{HCO}_{3}$ were also significantly associated with nCPAP outcome among study participants $(p<0.0001)$.

\begin{tabular}{|c|c|c|c|c|}
\hline \multirow{2}{*}{\multicolumn{2}{|c|}{ Study Variables }} & \multicolumn{2}{|c|}{ nCPAP Outcome $(n=172)$} & \multirow{3}{*}{$\begin{array}{l}\text { P-Value } \\
0.4990\end{array}$} \\
\hline & & \multirow{2}{*}{$\begin{array}{c}\text { Successful }(n=143) \\
74(51.7 \%)\end{array}$} & \multirow{2}{*}{$\begin{array}{c}\text { Unsuccessful (n=29) } \\
17(58.6 \%)\end{array}$} & \\
\hline Gender & Male & & & \\
\hline \multirow[b]{2}{*}{ Gestational Age (weeks) } & $28-30$ & 27 (18.9\%) & 21 (72.4\%) & \multirow[b]{2}{*}{$<0.00001$} \\
\hline & $31-32$ & $83(58.0 \%)$ & $6(20.7 \%)$ & \\
\hline \multirow[t]{2}{*}{ Birth Weight (g) } & $1000-1500$ & 87 (60.8\%) & $10(34.5 \%)$ & \multirow[t]{2}{*}{$<0.00001$} \\
\hline & $1501-2000$ & $46(32.2 \%)$ & $5(17.2 \%)$ & \\
\hline \multirow{2}{*}{$\begin{array}{l}\text { Radiological Grading of } \\
\text { RDS }\end{array}$} & Mid & 26 (18.2\%) & $1(3.4 \%)$ & \multirow[b]{2}{*}{$<0.00001$} \\
\hline & Moderate & $89(62.2 \%)$ & $8(27.6 \%)$ & \\
\hline \multirow{2}{*}{$\begin{array}{l}\text { Arterial Blood Gas } \\
\text { Parameters }\end{array}$} & $\mathrm{PCO}_{2}($ Mean + SD $)$ & $31.82+6.18$ & $37.64+8.49$ & $<0.0001$ \\
\hline & $\mathrm{HCO}_{3}($ Mean+SD) & $20.681+1.25$ & $18.724+0.72$ & $<0.0001$ \\
\hline
\end{tabular}

Table-II. Distribution of nCPAP outcome with respect to study variables among study participants. 


\section{DISCUSSION}

In the present study, 83.1\% neonates with RDS were successfully managed using early nCPAP while remaining $16.9 \%$ required more invasive mechanical ventilation. Different modes of CPAP have been found to have different results in the previous studies. Kamper et al found success rate of $84 \%$ in RDS with CPAP system used with a binasal tube. ${ }^{12}$ Failure rate of $16 \%$ was the lowest reported with any CPAP system till then. Gitterman et al experienced early use of nCPAP in very low birth-weight neonates and found significant reduction in intubation rate after introduction of nCPAP (30\% vs 53\%, $p=0.016) .{ }^{13}$ Another study by Narendran $\mathrm{V}$ et al recorded that early bubble CPAP reduced the need for mechanical ventilation $(p<0.001)$ with no increased complications. ${ }^{14}$ One study by Nair et al showed failure rates of $10.7 \%$ in newborns with respiratory disease. They used nasal CPAP using Benveniste's valve. ${ }^{15}$ Urs et al found that CPAP proved to be efficacious among $80 \%$ cases with RDS. ${ }^{16}$ Saxena et al noted a comparatively lesser number of neonates $(61.2 \%)$ to have successful outcome of CPAP while remaining $38.8 \%$ were needed to be shifted to mechanical ventilation. ${ }^{17}$

In the present study, we found that $52.9 \%$ neonates with RDS were male and $47.1 \%$ female but gender did not influence the nCPAP outcome $(p>0.4990)$. Sandri $F$ et al and Urs et al also witnessed that gender did not impact CPAP outcome $(p>0.05) .{ }^{16,18}$

In the present study, we evaluated outcome of neonates with regards to gestational age and found that neonates who had unsuccessful outcome of early nCPAP, $72.4 \%$ neonates were having gestational age less than 31 weeks. As the gestational age increased, we noted significantly successful outcomes. Urs et al have found better outcome in gestational age of 32-34 weeks $(p<0.001) .{ }^{16}$

We also noted that among neonates who had unsuccessful outcome, $48.3 \%$ had birth-weight below 999 grams. Hameed et al from Iraq also highlighted lower birth weight to be significantly associated with poor outcomes of CPAP. ${ }^{19}$ On the other hand, Aly $\mathrm{H}$ et al studied outcome of nCPAP in extremely low birth weight babies and found no significant trends in mortality rate among the baseline group and the 3 groups after the institution of the nasal CPAP practice. Nasal CPAP management increased in the surviving infants over time, whereas the need for surfactant treatment decreased. ${ }^{20}$

Blood gas analysis was the other parameter, which helped us to decide success and failure on early nasal CPAP. In our study we found that babies on CPAP had significant improvement in oxygenation $(p<0.0001)$. With this we could reduce $\mathrm{FiO}_{2}$ significantly and wean down the babies. There are very few studies, which have looked into the effect of CPAP on oxygenation. First study by Gregory et $\mathrm{al}^{7}$ demonstrated significant improvement in $\mathrm{PaO}_{2}$; other parameters like $\mathrm{PCO}_{2}$ and $\mathrm{pH}$ did not varied much. Another study by Harris $\mathrm{H}$ et al noted improved levels of $\mathrm{PaO}_{2}$ $\mathrm{p}<0.05)$ as well as major changes in $\mathrm{PaCO}_{2}$ or $\mathrm{pH}$. Improvement in $\mathrm{PaO}_{2}$ facilitated reduction of $\mathrm{FiO}_{2}$ in less than $20 \mathrm{~h}^{21}$

Babies were classified as mild, moderate and severe grade of RDS based on radiological appearance and we studied in which group of babies early nasal CPAP is more effective. Almost all of the neonates who improved on nCPAP belonged to moderate RDS group. Early nCPAP seemed effective in mild and moderate RDS. It may not be a replacement for assisted respiratory support (ventilation) in severe cases of RDS. ${ }^{22}$ One study by Schmid $R$ et al who analyzed data based on radiological appearance and showed that CPAP was an effective method in newborns with all grades except severe RDS. ${ }^{23}$ Another study by Urs et al, conclude that CPAP is effective in mild and moderate grade RDS. ${ }^{16}$

There were few limitations of this study as well. We did not have a comparative group. As per the initial protocol of this study, we could not note complications of early nCPAP among our patients. Further studies involving larger groups of patients, with optimal monitoring facilities and multiple settings will further guide us about advantages of different options available for the 
treatment of neonates with RDS.

\section{CONCLUSION}

Early Nasal CPAP is safe, inexpensive and effective means of respiratory support in neonates with RDS. Early nasal CPAP is useful especially in mild and moderate grade RDS. It may not be a replacement for assisted respiratory support (ventilation) in severe RDS. In developing countries like Pakistan where there is a high burden of prematurity, use of early nasal CPAP which is simple, non-invasive, has low capital outlay and does not require expertise, is the option for us where most places cannot provide invasive ventilation.

Copyright@ 02 Nov, 2020.

\section{REFERENCES}

1. Sweet LR, Keech C, Klein NP, Marshall HS, Tagbo BN, Quine $\mathrm{D}$, et al. Brighton collaboration respiratory distress in the neonate working group. Respiratory distress in the neonate: Case definition \& guidelines for data collection, analysis, and presentation of maternal immunization safety data. Vaccine. 2017; 35:6506-17.

2. Course $\mathrm{C}$, Chakraborty $\mathrm{M}$. Management of respiratory distress syndrome in preterm infants in Wales: A full audit cycle of a quality improvement project. Sci Rep 2020; 10:3536.

3. March of Dimes, PMNCH, Save the Children, WHO. Born too soon: The global action report on preterm birth. Eds CP Howson, MV Kinney, JE Lawn. World Health Organization. Geneva, 2012.

4. Bhutta ZA, Yusuf K. Neonatal respiratory distress syndrome in Karachi: Some epidemiologic considerations. Paediatr Perinat Epidemiol 1997; 11:37-43.

5. Khan MR, Maheshwari PK, Shamim H, Ahmed S, Ali SR. Morbidity pattern of sick hospitalized preterm infants in Karachi, Pakistan. J Pak Med Assoc 2012; 62:386-8.

6. Papadopoulos MD, swyes PR. Assisted ventilation in terminal hyaline membrane disease. Arch Dis Child 1964; 39:481-84.

7. Gregory GA, Kitterman JA, Phibbs RH, Tooley WH, Hamilton WK, et al. Treatment of the idiopatic respiratory-distress syndrome with continuous positive airway pressure. N Engl J Med 1971; 284:1333-40.
8. Devi P, Raja R, Kumar R, Shah A, Ansari SI, Kumar B. Invasive versus non-invasive positive pressure ventilation in chronic obstructive pulmonary disease complicated by acute respiratory failure. Cureus. 2019; 11:e5418.

9. Carns J, Kawaza K, Liaghati-Mobarhan S, et al. Neonatal CPAP for respiratory distress across malawi and mortality. Pediatrics. 2019; 144:e20190668.

10. Milliner, B.H., Bentley, S. \& Du Canto, J. A pilot study of improvised CPAP (iCPAP) via face mask for the treatment of adult respiratory distress in lowresource settings. Int J Emerg Med 2020; 12:7.

11. Anwaar O, Hussain M, Shakeel M, Baig MM. Outcome of use of nasal continuous positive airway pressure through infant flow drivers in neonates with respiratory distress in a tertiary care hospital in Pakistan. J Ayub Med Coll Abbottabad 2018; 30(4):5115.

12. Kamper J, Ringsted C. Early treatment of idiopathic respiratory distress syndrome using binasal continuous positive airway pressure. Acta Pediatr Scand. 1990; 79:581-6.

13. Gitterman MK, Fusch C, Gitterman AR et al. Early nasal continuous positive airway pressure treatment reduces the need for intubation in very low birth weight infants. Eur J Pediatr. 1977; 156:384-8.

14. Narendran V, Donovan EF, Hoath SB et al. Early bubble CPAP and outcomes in ELBW preterm infants. J Perinatol 2003; 23:195-9.

15. Nair PMC, Reddy VG, Jaya s. Neonatal CPAP - Our experience with Benveniste's valve. Indian Pediatrics. 2002; 851-5.

16. Urs PS, Firdose K, Maiya PP. Bubble CPAP - A primary respiratory support for respiratory distress syndrome in newborns. Indian Pediatrics 2009; 46:409-11.

17. Saxena A, Thapar RK, Sondhi V, Chandra P. Continuous positive airway pressure for spontaneously breathing premature infants with respiratory distress syndrome. Indian J Pediatr 2012; 79:1185-91.

18. Sandri F, Ancora G, Lanzoni A, P Tagliabue, Colnaghi $M$, Ventura $M$, Rinaldi $M$, et al. Prophylactic nasal continuous positive airways pressure in newborns of 28-31 weeks gestations: Multicenter randomized controlled clinical trial. Arch Dis Child Fetal Neonatal Ed. 2004; 89:F394-8. 
19. Hameed NN, Abdul Jaleel RK, Saugstad OD. The use of continuous positive airway pressure in preterm babies with respiratory distress syndrome: A report from Baghdad, Iraq. J Matern Fetal Neonatal Med $2014 ; 27: 629-32$.

20. Aly H, Milner JD, Patel K, El-Mohandes AA. Does the experience with the use of nasal continuous positive airway pressure improve over time in extremely low birth weight infants? Pediatrics 2004; 9:697-702.

21. Harris $H$, Wilson $S$, Brans $Y$, Wirtschafter D, Cassady G. Nasal continuous positive airway pressure. Improvement in arterial oxygenation in hyaline membrane disease. Biol Neonate. 1976; 29: 231-7.
22. Alfarwati TW, Alamri AA, Alshahrani MA, Al-Wassia $H$. Incidence, risk factors and outcome of respiratory distress syndrome in term infants at Academic Centre, Jeddah, Saudi Arabia. Medical Archives (Sarajevo, Bosnia and Herzegovina). 2019; 73:183-6.

23. Schmid ER, Dangel PH, Duc GV. The use of nasal CPAP in newborns with RDS. Eur $\mathrm{J}$ Intensive Care Med. 1976; 2:125-30.

\section{AUTHORSHIP AND CONTRIBUTION DECLARATION}

\begin{tabular}{|c|l|c|}
\hline Sr. \# & \multicolumn{1}{|c|}{ Author(s) Full Name } & Contribution to the paper \\
\hline 1 & Abdur Rehman & Author(s) Signature \\
2 & Ahmad Iqbal Quddusi & Introduction, Discussion, \\
3 & Aashee Nadeem & Results. \\
4 & Nazia Fatima & \\
5 & Imran lqbal &
\end{tabular}

